\title{
基于变形时间效应的高速铁路地基压缩层厚度 计算方法
}

\author{
熊勇 ${ }^{*}$, 罗强, 张良, 蒋良潍, 朱江江 \\ 西南交通大学高速铁路线路工程教育部重点实验室, 成都 610031 \\ *E-mail: yongx1118@163.com \\ 收稿日期: 2014-03-26; 接受日期: 2014-06-03 \\ 国家重点基础研究发展计划(批准号: 2013CB036204)资助项目
}

\begin{abstract}
摘要路堤荷载作用下地基变形是高速铁路路基沉降的主要来源, 地基有时间效应的变形 是引起高速铁路长期服役性能劣化的核心因素，掌握具有变形时间效应的地基土层区域是合 理计算地基工后沉降、优化地基加固方案的技术关键. 基于分形的无标度特性, 确立塑性变形 速率随时间的分形关系, 揭示了地基土变形随荷载水平呈现快速稳定、长期稳定、长期破坏 和快速破坏的四种演化状态类别, 提出了表征变形速率变化快慢的土体变形状态“分维数判 别法”; 开展了单元结构填土模型和三轴流变试验, 获得了中低压缩性粉质黏土的变形状态荷 载阈值及其与抗剪强度或极限承载力的比值; 基于摩尔-库伦准则, 采用强度折减方法, 获得 了地基土变形状态强度参数, 结合地基土中应力, 得到了由库伦强度理论表达的变形状态控 制方程, 明确了地基沿深度具有时间效应变形区域的深度即为基于变形时间效应的地基压缩 层厚度。提出的“时间效应法”确定压缩层厚度为进一步完善高速铁路的地基沉降计算提供了 理论依据和实验支撑.
\end{abstract}

\section{关键词}

高速铁路

路堤地基

变形时间效应

压缩层厚度

土工流变试验

\section{1 引言}

高速铁路的全面建设和正常运行对促进国民经 济发展有重要作用, 其对基础结构在动力、静力荷载 和环境作用下的强度、稳定性和耐久性 ${ }^{[1]}$ 要求和建设 标准都远高于普通铁路. 其中, 控制地基工后沉降发 展是保持轨道结构的良好几何平顺性, 保证高速铁 路线路长期服役性能的关键. 天然黏土地基因上部 荷载作用在地基变形时间效应区域产生的变形是工 后沉降主要来源 ${ }^{[2]}$. 合理确定压缩层厚度, 满足无砟 轨道高速铁路地基工后沉降小, 变形收玫速度快 ${ }^{[3]}$ 的
新要求, 是控制地基工后沉降, 从而保证无砟轨道高 速铁路长期服役性能的技术核心，而且对优化高速 铁路地基设计、获得技术和经济统一 ${ }^{[3]}$ 的地基处理方 案有极大的现实意义.

\section{2 确定地基压缩层厚度常用方法}

我国在很长一段时期内主要采用应力比控制法 确定地基压缩层厚度, 现行部分技术规范 ${ }^{[4-9]}$ 仍在沿 用, 并相当有经验. 该方法计算得到的地基压缩层厚 度随 $p$ 或者 $b$ 的增加而无限增长，而工程实践表明压

引用格式: 熊勇, 罗强, 张良, 等. 基于变形时间效应的高速铁路地基压缩层厚度计算方法. 中国科学: 技术科学, 2014, 44: 755-769 Xiong Y, Luo Q, Zhang L, et al. Calculating method based on deformation time effect on thickness of compressible stratum in high-speed railway foundation (in Chinese). Sci Sin Tech, 2014, 44: 755-769, doi: 10.1360/N092014-00087 
缩层厚度随 $p$ 或者 $b$ 的增加是有限的 ${ }^{[10]}$. 对此, 一些 技术规范 ${ }^{[11 ~ 13]}$ 采用变形比控制法确定压缩层厚度; 另外, 也有学者 ${ }^{[14]}$ 考虑土体结构性, 提出了土体结构 强度控制法确定压缩层厚度的理论方法.

\section{1 应力比控制法}

采用应力比控制法确定地基沉降计算深度的基 本思路是, 自基础底面起算, 取附加应力 $\sigma_{z}$ 与自重应 力 $\sigma_{c z}$ 比值等于某一比例系数 $\psi$ 时的深度作为地基压 缩层厚度 $z_{n},(1)$ 式为其控制方程.

$$
\sigma_{z} \leqslant \psi \sigma_{c z} .
$$

不同行业和地区根据各自的特点对 $\psi$ 有不同的 规定.《铁路工程地基处理技术规程》 ${ }^{[4]}$ 规定, 高速铁 路 $\psi=0.1$, 其他铁路 $\psi=0.2$, 而对所有铁路的软土地 基, 《铁路特殊路基设计规范》 ${ }^{[5]}$ 均取 $\psi=0.1$; 《港口工 程地基规范》 ${ }^{[6]}$ 规定, 常规情况 $\psi=0.2$, 有软土层时 $\psi=0.1 ;$ 《北京地区建筑地基基础勘察设计规范》 ${ }^{[7]}$ 对中低压缩性土 $\psi=0.2$, 对高压缩性土 $\psi=0.1$; 上海 市标准 《地基基础设计规范》 ${ }^{[8]}$ 规定 $\psi=0.1$; 福建省 标准《建筑地基基础勘察设计规范》 ${ }^{[9]}$ 规定, 地基压 缩模量 $E \geqslant 6 \mathrm{MPa}$ 时 $\psi=0.2$, 其他 $\psi=0.1$; 文献[15]介绍 前苏联规范规定, 地基变形模量 $E \geqslant 5 \mathrm{MPa}$ 时 $\psi=0.2$, 否则 $\psi=0.1$, 同时对大型水工建筑按作用于基底的总 应力计算, 取 $\psi=0.5$.

可见, 应力比值法的系数 $\psi$ 取值与土性和建筑 物标准有关. 对于高压缩性土和变形要求严格工程, 取 $\psi=0.1$; 在中低压缩性土地基上建造的一般民用工 程, 取 $\psi=0.2$; 对于地基条件优良的大型水利工程等, 甚至将 $\psi$ 的取值放宽到 0.5 .

\section{2 变形比控制法}

采用变形比控制法确定压缩层厚度的基本思路 是, 自基础底面算起, 取深度 $z$ 向上取 $\Delta z$ 厚度的土层 计算压缩量 $\Delta S_{n}^{\prime}$ 与 $z$ 范围内土层的总压缩量的比值等 于 0.025 时的地基沉降计算深度 $z$ 作为压缩层厚度 $z_{n}$. (2)式为其控制条件.

$$
\Delta s_{n}^{\prime} \leqslant 0.025 \sum_{i=1}^{n} \Delta s_{i}^{\prime},
$$

式中, $\Delta s_{i}^{\prime}$ 为第 $i$ 层土的计算压缩量 $(\mathrm{mm})$.

同时, 为考虑基础宽度 $b$ 的影响，部分规范 ${ }^{[11 ~ 13]}$ 对 $\Delta z$ 按(3)式进行修正, 以满足 $z_{0} / b$ 随 $b$ 增大而减小
的基本实测规律.

$$
\Delta z=0.3(1+\ln b), \quad(b>1) .
$$

变形比控制法综合考虑了基底接触压力和地基 土性对压缩层厚度的影响，结合(3)式对 $\Delta z$ 的修正, 能比较好地反映实测压缩层厚度随基础宽度 $b$ 的非 线性增长规律.

\section{3 经验法}

钟亮 ${ }^{[10]}$ 以允许承载力作为板底压力, 对淤泥质 软土和非软土进行荷载板试验并观测不同深度处沉 降 $S_{z}$, 取 $S_{z}$ 为板底沉降 $S_{0}$ 的 $5 \%$ 对应的深度作为压缩 层厚度 $z_{n}$, 结合工程实测资料, 提出了基础宽度 $b$ 在 10 50 m 内范围估算压缩层深度的经验公式(4), 并列 入了有关规范 ${ }^{[1113]}$ 供参考使用.

$$
z_{n} / b=2.5-0.4 \ln b .
$$

何䝠华和季婉如 ${ }^{[15]}$ 将地基视为均质土层, 按 《工 业与民用建筑地基基础设计规范》(TJ-74),基于变形 比控制法(取 $\Delta z=1 \mathrm{~m}$ ), 计算不同形式和尺寸基础压缩 层厚度 $z_{n}$, 通过总结 $z_{n}$ 与 $b$ 的变化规律, 提出对方形 和矩形基础压缩层厚度按经验公式(5)计算 $z_{n}$, 带状 基础则按公式(6)计算.

$$
\begin{gathered}
z_{n}=\left(z_{m}+\xi b\right) \beta, \\
z_{n}=(10.5+0.87 b) \beta .
\end{gathered}
$$

式中, $z_{m}$ 和 $\xi$ 为与基础长宽比 $l / b$ 相关的经验系数, $\beta$ 为 土性折减系数. 该方法在《北京地区建筑地基基础 勘察设计规范》 ${ }^{[7]}$ 中用于确定高层建筑地基沉降计算 深度.

\section{4 土体结构强度控制法}

夏正中 ${ }^{[14]}$ 根据土体结构强度 $p_{c z}$ 提出了地基有效 压缩层厚度的确定方法. $p_{c z}$ 随地基深度增加, 满足库 伦准则, 由(7)式计算; 并认为土体承受的附加应力 $\sigma_{z}$ 小于 $p_{c z}$ 时, 不会产生显著压缩变形, 可采用基于此 原理的(8)式确定压缩层厚度.

$$
\begin{gathered}
p_{c z}=c_{z}+p_{z}^{\prime} \tan \varphi_{z}, \\
\sigma_{z} \leqslant p_{c z},
\end{gathered}
$$

式中, $p_{z}^{\prime}$ 为深度 $z$ 处自重应力力, $c_{z}$ 和 $\varphi_{z}$ 为深度 $z$ 处 结构强度参数.

该方法以土体结构强度为核心参数, 对土体变 形的内在机理进行了解释, 得到的压缩层厚度与地 基土性和上部荷载密切相关，但未明确提出获得 $c_{z}$ 
和 $\varphi_{z}$ 的方法.

上述方法均以地基总沉降计算为压缩层厚度确 定目标. 其中, 应力比法只考虑了土中应力分布对压 缩层厚度的影响; 变形比法强调了附加应力与地基 土性对压缩层厚度的共同影响; 结构强度控制法以 附加应力对土体变形的影响是否显著作为压缩层厚 度的确定原则. 路基工程以工后沉降为控制目标, 尤 其是高速铁路无砟轨道路基因其不可维修性, 对工 后沉降要求极其严格, 一般地段路基工后沉降不超 过 $15 \mathrm{~mm}$, 路基与其他结构物过渡地段工后沉降差 异不超过 $5 \mathrm{~mm}^{[1]}$. 地基沉降计算的目的是使地基工 后沉降满足设计要求, 地基随时间产生的变形是路 基工后沉降的主要组成部分, 在确定地基压缩层厚 度时应只考虑具有时间效应变形的对应土层.

为得到地基变形时间效应区域土层厚度, 开展 室内单元模型实验对土体塑性变形速率进行研究, 分析塑性变形速率随时间发展关系, 对土体变形演 化状态特征进行划分和判别, 进而获得地基土体变 形状态荷载阈值; 借鉴摩尔-库伦原理, 得到地基土 变形状态强度参数, 结合地基土中应力, 将地基划分 为变形时间效应区域和非变形时间效应区域, 得到 地基时间效应压缩层厚度，从而构建基于变形时间 效应的高速铁路地基压缩层厚度的计算方法.

\section{3 土体变形时间效应特征及状态划分}

土体变形特征包括无时间效应变形和有时间效 应变形的两种基本状态，土体变形具有时间效应主 要属于蠕变研究范畴. 土体蠕变过程的非线性发展 趋势是土性和荷载相互耦合作用的宏观反映, 随荷 载不同呈现不同的蠕变特性.

维亚洛夫 ${ }^{[16]}$ 按应力水平将黏土变形划分为弹 性、弹塑性和蠕变等状态. 对蠕变则进一步划分为衰 减蠕变和非衰减蠕变. 衰减蠕变过程中蠕变速率随 时间减小并最终趋于零, 蠕变变形量最终趋于定值; 非衰减蠕变过程包含减速阶段、稳定阶段和加速阶段, 对应的蠕变速率随时间分别有减速、恒量和加速三种 情况, 蠕变变形最终发散. 并指出, 应力小于蠕变界 限(土体结构强度) 时, 蠕变不发生; 应力小于土体长 期强度, 只出现衰减蠕变, 变形随时间逐渐趋向稳定值, 应变速率随时间趋于零; 应力略大于长期强度, 只出 现非衰减蠕变过程中的减速阶段, 应变速率随时间
减小并趋于恒量, 随着应力继续增大, 减速阶段时间 越来越短, 会出现稳定阶段和加速阶段; 应力接近极 限强度时, 几乎不出现减速阶段和稳定阶段, 直接进 入加速阶段.

陈宗基 ${ }^{[17]}$ 提出土体变形存在 3 个强度界限值 $f_{1}$, $f_{2}$ 和 $f_{3}$. 土体承受的荷载 $\sigma \leqslant f_{1}$ 时, 变形可以忽略; $f_{1}<\sigma \leqslant f_{2}$ 时变形为弹性; $f_{2}<\sigma \leqslant f_{3}$ 变形为黏弹塑性; $\sigma>f_{3}$ 土体结构崩解破坏, 并认为该值是应力屈服值, 可作 为长期强度指标.

孙钧 ${ }^{[2]}$ 针对上海软土蠕变特性提出 3 个蠕变特征 值 $\sigma_{1 \mathrm{~s}}, \sigma_{2 \mathrm{~s}}$ 和 $\sigma_{p}$. 指出, $\sigma \leqslant \sigma_{1 \mathrm{~s}}$ 时, 变形不具有时间效应; $\sigma_{1 \mathrm{~s}}<\sigma \leqslant \sigma_{2 \mathrm{~s}}$ 的蠕变是衰减型, 变形趋于稳定; $\sigma_{2 \mathrm{~s}}<\sigma \leqslant \sigma_{p}$ 的蠕变出现黏滞流动阶段, 变形不能稳定, 最终导致 破坏; $\sigma>\sigma_{p}$ 时土体在很短时间内破坏.

范庆忠等人 ${ }^{[18]}$ 提出起始蠕变应力阈值 $\sigma_{1}$ 和蠕变 破坏强度 $\sigma_{2}$, 将含油泥岩蠕变划分为无明显蠕变、衰 减蠕变和加速蠕变三种状态. $\sigma<\sigma_{1}$ 时, 变形会很快完 成; $\sigma_{1}<\sigma<\sigma_{2}$ 时蠕变速率衰减发展, 变形可能发散也 可能收玫; $\sigma<\sigma_{2}$ 时蠕变速率加速发展, 短时间变形快 速增加, 土体因达到极限应变而破坏.

吴紫汪等人 ${ }^{[19]}$ 利用 $\mathrm{CT}$ 技术基于冻土细观结构 的强化和弱化特征, 将蠕变过程分为衰减蠕变和非 衰减蠕变. 认为土体在蠕变过程中, 结构强化与结构 弱化同时在发生, 其中结构强化和结构弱化分别对 衰减蠕变和非衰减蠕变过程起主导作用.

上述研究表明, 土体(或岩石)存在的结构强度是 其发生蠕变的起始界限, 长期强度可作为蠕变收玫 与发散的界限强度，而蠕变进入快速破坏状态时的 荷载水平应在极限强度附近. 按结构强度、长期强度 和极限强度将土体变形划分为快速稳定 (无时间效 应)、长期稳定、长期破坏和快速破坏符合土体变形 基本规律. 表 1 为对已有研究成果中有关土体变形时 间效应特征及状态划分的描述和汇总。

\section{4 土体变形时效性的分形特征及状态判别}

工程材料有各自不同的内在结构, 存在类型各 异、数量不一、分布不均等固有缺陷, 其力学性能与 之密切相关 ${ }^{[20]}$. 土体材料的变形时间效应属于土力 学的流变问题研究范畴, 具有显著的非线性特征. 作 为能量开放体系的流变土体在承受荷载作用时，由于 蠕变使土颗粒之间产生摩擦效应而导致能量耗散 ${ }^{[21]}$, 


\section{表 1 土体变形状态划分}

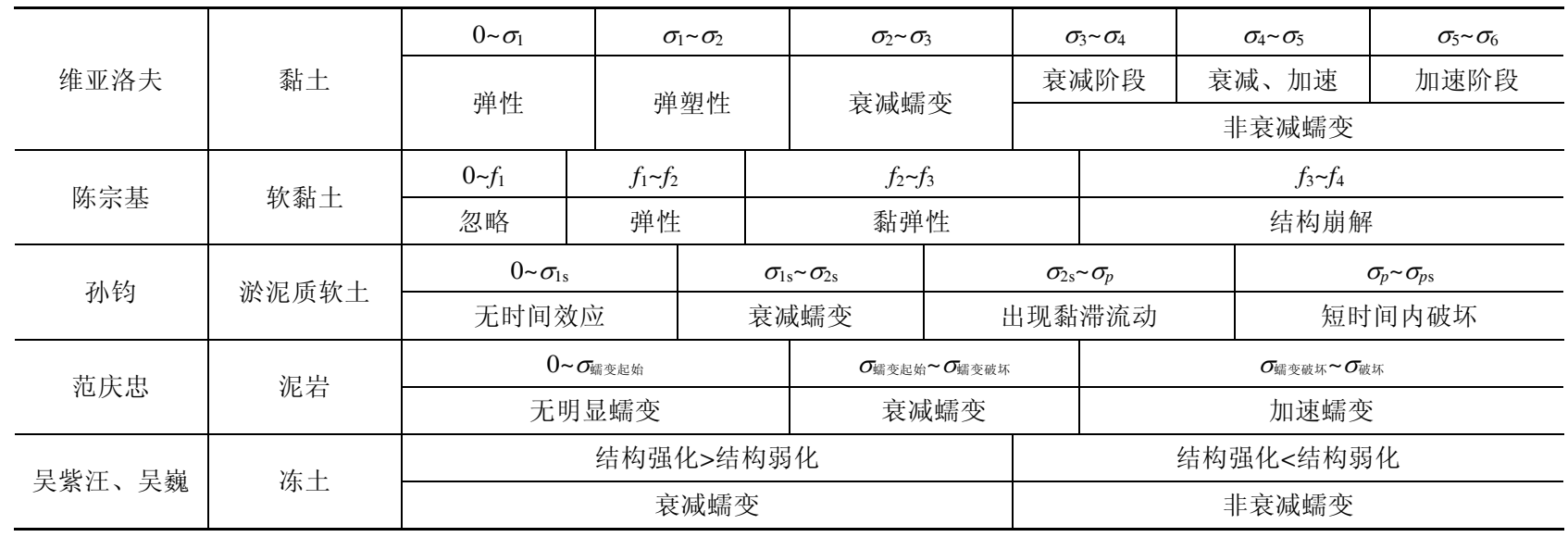

这就决定了土体蠕变过程属于远离热力学平衡态下 的复杂非线性系统 ${ }^{[20]}$. 因此, 应采用非线性科学方法 对土体变形时间效应进行研究.

目前非线性科学中的分形理论已经广泛应用于 自然科学和工程技术领域, 如物理学、地学、材料科 学与工程等 ${ }^{[22]}$. 借助分形理论研究岩土材料的内在 结构特征及其与宏观力学响应之间的联系, 已取得 了初步进展. 文献[23]指出 Thompson 等人通过扫描 电镜和光学显微镜对砂岩孔隙进行量测, 发现孔隙 空间具有分形特性, 并基于分形统计方法得出孔隙 率 $\phi$ 与分维数 $D$ 之间满足(9)式的关系.

$$
\phi=A\left(L_{1} / L_{2}\right)^{3-D},
$$

式中, $L_{1}$ 为孔隙体积单元 $\left(\mathrm{m}^{3}\right), L_{2}$ 为孔隙体积尺度 $\left(\mathrm{m}^{3}\right)$, $A$ 为常数.

谢和平 ${ }^{[24]}$ 研究了材料损伤演化过程的分形特性, 以分维数作为反映材料损伤程度的特征量, 并对大 理岩和页岩在损伤过程中的裂纹扩展进行分形维数 量测, 得到裂纹扩展分形维数 $D$ 与外加荷载 $\sigma$ 之间存 在(10)式关系, 并提出了 $D=1$ 是裂纹由有限扩展向无 限发展过渡的临界点.

$$
\sigma / \sigma_{c}=C_{1}+C_{2} D,
$$

式中, $\sigma_{\mathrm{c}}$ 为破坏荷载, $C_{1}, C_{2}$ 为材料常数.

利用分形理论对岩石材料的孔隙空间和荷载作 用下的裂纹发展规律进行的研究表明, 以分维数对 材料宏观物理性质与力学响应的演化特征进行描述, 能较为方便地对材料性质变化全过程进行状态区分.

工程结构物的地基沉降随时间发展历程符合统
计分形的 Pareto 定律 ${ }^{[20]}$, 绝大部分沉降发生在前期 较短的时间内，在长期使用年限内的大部分时间，仅 发生极少量的工后沉降. 根本原因是变形速率在前 期相对较大，之后随时间迅速衰减. 要区分地基工 后沉降发展状态，必须研究变形速率随时间的发展 规律.

对某一荷载水平下塑性变形发展过程按时间标 度 $\delta=1 \mathrm{~h}, \delta=2 \mathrm{~h}$ 和 $\delta=3 \mathrm{~h}$ 得到双对数坐标下的塑性变 形速率 $v$ 随时间 $t$ 的变化曲线, 如图 1 所示.

由图可见，塑性变形速率在相对准确的时间区 域内满足:

$$
v(t) \propto t^{-D} .
$$

按 Mandelbrot 法则 ${ }^{[20]}$, 时间标度 $\delta=1 \mathrm{~h}, \delta=2 \mathrm{~h}$ 和 $\delta=3 \mathrm{~h}$, 速率大小随时间变化的幂指数分别为 0.911 , 0.917 和 0.96 , 极差为 0.04 可以认为分布是相似的. 也就是说, 适当的改变时间标度 $\delta$, 就可以成为同样 的分布. 在这个时间区域内, $D$ 是一个相对稳定的非 整数, 表现出无时间标度性, 并且局部变化趋势与整 体的变化趋势相似, 相对较短的试验时间 (24h)内和 较长的时间内的变化趋势相似 ${ }^{[20]}$. 说明了塑性变形 速率在时间上具有分行特性，模型试验时间 $24 \mathrm{~h}$ 内 的塑性变形速率发展规律与整个塑性变形发展时间 内的规律相似.

根据分形的标度率, 可得

$$
D=\log v(t) / \log (1 / t) .
$$

根据塑性变形速率 $v$ 和时间 $t$ 的双对数的斜率就 可以直接求得塑性变形速率的分维值为 $D$. 


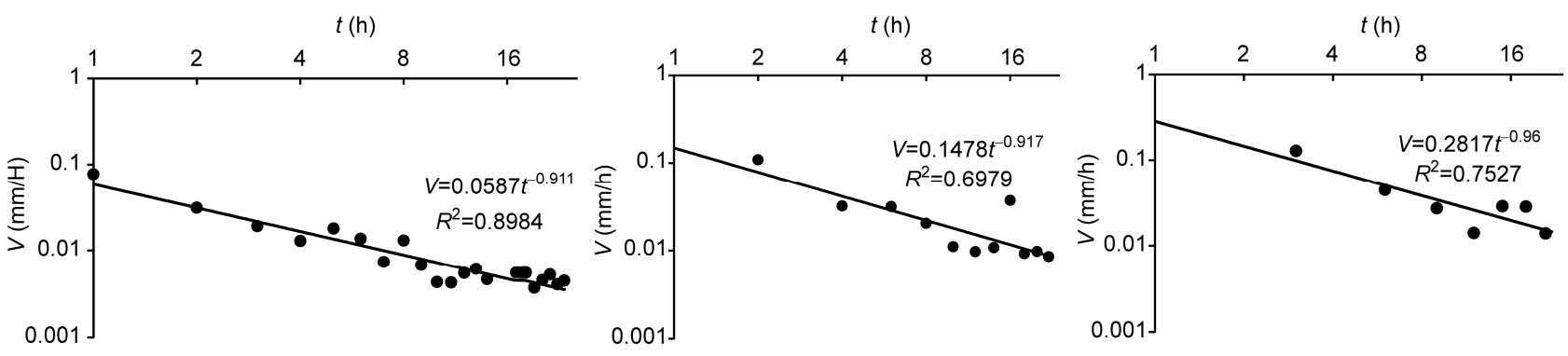

图 1 不同 $\delta$ 得到的 $v-t$ 关系(双对数坐标系)

(a) $v-t$ : $\delta=1 \mathrm{~h}$; (b) $v-t: \delta=2 \mathrm{~h}$; (c) $v-t: \delta=3 \mathrm{~h}$

对于塑性变形过程, 时间尺度 $\delta \geqslant \delta_{\text {min }}$, 无法趋于 0 , 决定了不能通过积分得到变形值. 同时, 初始条 件包含的信息随时间逐渐丧失, 速率发展对初始条 件极具敏感性, 从而造成的速率长程预测不准确性 ${ }^{[25]}$, 决定对塑性变形大小通过(8)式进行预测不具有 客观性，只能通过分段累和求得.

$D$ 是实测数据点对 $\left(v_{i}, t_{i}\right), i=1,2, \cdots, i, \cdots N$ 的关联 维数, 反映数据点对在相平面内或线上侵占程度和 分布均匀度 ${ }^{[25]}$ : 若均匀分布在整个平面, $D=2$, 不均 匀分布在整个平面内, $D<2$; 若均匀分布在某条线上, $D=1$, 不均匀分布在某条直线上, $0<D<1$. 塑性变形 速率的时间序列是土体变形过程中各要素相互作用 的结果 ${ }^{[25]}$, 塑性变形速率与时间的分维数的几何区 间为 $0 \sim 2$ 同时, $D$ 为塑性变形速率对时间的敏感性指 数 ${ }^{[26]}$. $D$ 越大, 变形对时间敏感性越高, 表现为速率 随时间衰减越快.

$D>2$ 时, 塑性变形速率对时间敏感性极高, 表现 变形发展对时间 $t$ 极为敏感, 前期发展绝大部分, 后 续相当一段时间内变形基本不发展, 塑性变形速率 对时间已经超出分形的几何区间, 变形不具有时间 效应，此时土体变形没有时间效应; $0<D<2$ 时, 塑性 变形速率随时间体现分形特性, 变形具有时间效应.

$D=0$ 时速率为一稳定值, 变形出现等速流动阶 段; $D<0$ 时, 速率随时间增加极快, 此时土体在破坏 前已经无法维持结构的平衡性 ${ }^{[24]}$, 塑性变形不体现 时间效应, 无分形特性, 如图 2 所示, 土体迅速破坏.

在塑性变形速率的时间分行区间内对塑性变形 进行分析, 由式 $v(t)=A t^{-D}$ 可得

$$
S(t)=\delta \cdot A(\delta)^{-D}+\delta \cdot A(2 \delta)^{-D} \ldots+\delta \cdot A(i \delta)^{-D},
$$

其中, $\delta$ 为时间标度 (h), $t=i \delta(\mathrm{h})$.

$\delta=1 \mathrm{~h}$ 时, (10)式即为

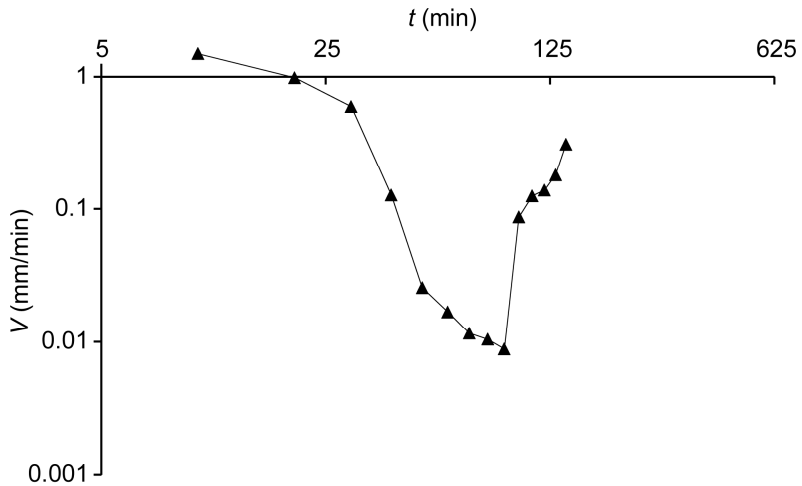

图 2 土体破坏前和破坏中 $v-t: p=0.8 \sigma_{f}$

$$
S(t)=A\left(^{-D}+2^{-D} \ldots+i^{-D}\right),
$$

当 $t \rightarrow \infty$ 时, $i \rightarrow \infty, S(t)=A \sum_{1}^{\infty} i^{-D}, D>1$ 收玫, $D \leqslant 1$ 发散.

综上分析，通过速率与时间分形的分维数 $D$ 来 反映变形时间效应, 描述塑性变形速率的时间敏感 性, 从而揭示了变形发展的四种变形演化状态 ${ }^{[27]}$, 并 建立变形演化状态的判别准则, 如表 2 所示.

\section{5 地基土变形时间效应的模型试验及状态 参数}

为得到土体变形状态荷载阈值, 设计了室内单

\section{表 2 变形状态判别准则}

\begin{tabular}{lll}
\hline 判别条件 & 变形状态 & \multicolumn{1}{c}{ 变形特性 } \\
\hline$D>2$ & 快速稳定 & 短时间内稳定 \\
$1<D<2$ & 长期稳定 & 有时间效应趋于稳定 \\
$0<D<1$ & 长期破坏 & 无时间效应趋于破坏 \\
$D<0$ & 快速破坏 & 短时间内破坏 \\
\hline
\end{tabular}


元结构填土模型, 进行逐级静力加载试验. 得到不同 压实系数土体模型在不同荷载水平下变形时程曲线 和回弹变形. 假定回弹变形不具有时间效应, 据此可 得模型在不同荷载水平下塑性变形速率随时间变化 曲线, 进行分形特性分析, 得到其分维数 $D$. 基于变 形状态判别准则, 可得模型土体变形状态阈值参数.

填土模型高度 $1.0 \mathrm{~m}$, 底面长宽均为 $0.7 \mathrm{~m}$, 在填 土模型表面中心位置放置直径为 $300 \mathrm{~mm}$, 厚度为 25 $\mathrm{mm}$ 的刚性加载板. 填土模型四周采用互不搭接的砖 墙砌筑, 砖墙外侧用砂袋堆砌, 构成柔性接触, 以模 拟地基半无限空间. 根据应力衰减计算规律, 模型边 界处应力衰减量大于 $95 \%$, 满足应力边界; 同时试验 测试的侧向水平位移数据显示, 在荷载强度小于 180 $\mathrm{kPa}$ 时, 模型侧向水平位移基本不会影响坚向变形, 当荷载强度大于 $180 \mathrm{kPa}$ 时, 侧向约束开始发挥作用 侧向变形从第五级开始出现明显的回弹加载过程, 且侧向变形明显增大, 此时侧向约束开始发挥作用. 测试 $K_{30}$ 时实验压力段为 $0 \sim 200 \mathrm{kPa}$, 由测试数据可 知, 模型侧向约束不会对 $K_{30}$ 值有实质性的影响, 从 而将 $K_{30}$ 值近似作为真实值. 由 $K_{30}$ 估算地基极限承 载力与试验得到的地基极限承载力接近可知, 模型 的侧向约束在后荷载大于 $180 \mathrm{kPa}$ 时, 能保证地基承 载力的可靠性.
为得到填土模型在不同荷载作用下的沉降变形 时间历程曲线, 在加载板表面如图 3 和 4 对称布置两 个位移计测量板底沉降, 并采用如图 3 所示的自行加 工设计的砝码-杜杆-量力环加载系统对填土模型进 行加载.

模型填土取自某客运专线铁路施工现场，参照 《铁路工程土工试验规程》 ${ }^{[28]}$ 对土体进行了液塑限、 颗粒密度、颗粒分析、重型击实(Z2)等试验, 测试数 据如表 3 和图 5(两组平行试验), 6 所示, 最大粒径小 于 $5 \mathrm{~mm}$. 其中, $0.075 \mathrm{~mm}$ 以下粒径占 $78.77 \%, 0.005$ $\mathrm{mm}$ 以下粒径占 $28.48 \%, 0.002 \mathrm{~mm}$ 以下粒径(胶粒)占

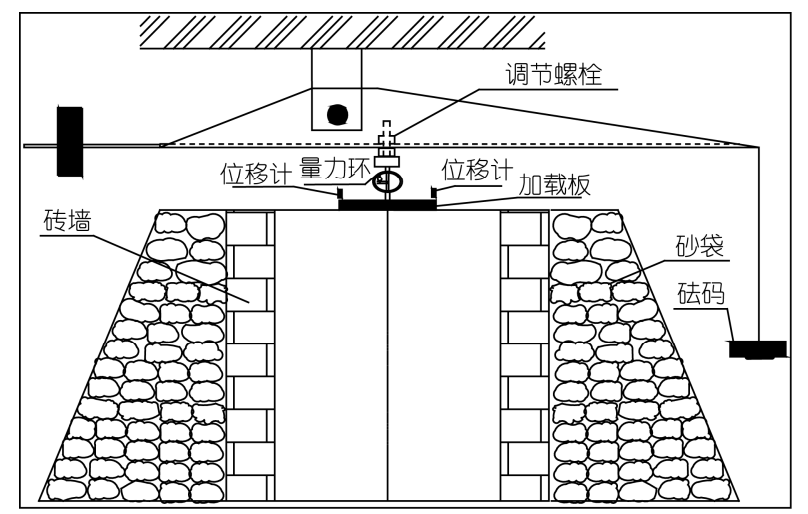

图 3 模型及加载设备剖面示意图

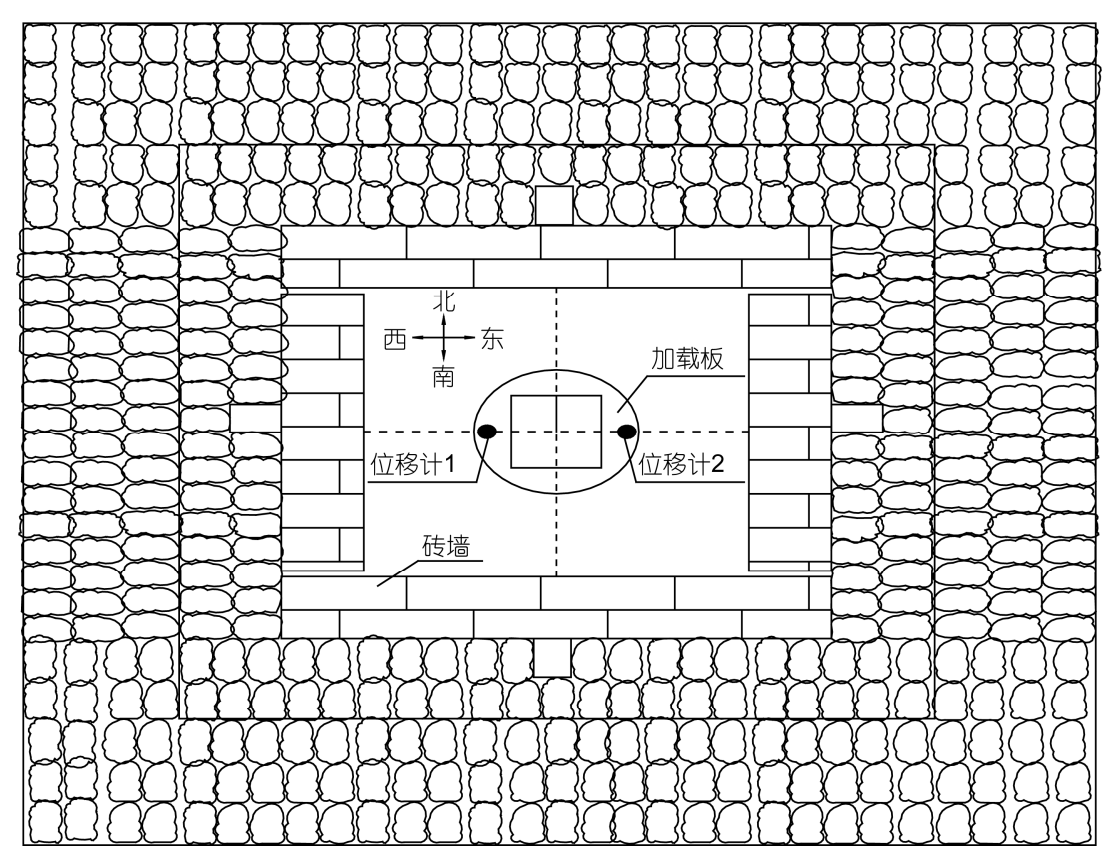

图 4 模型及测点布置平面示意图 


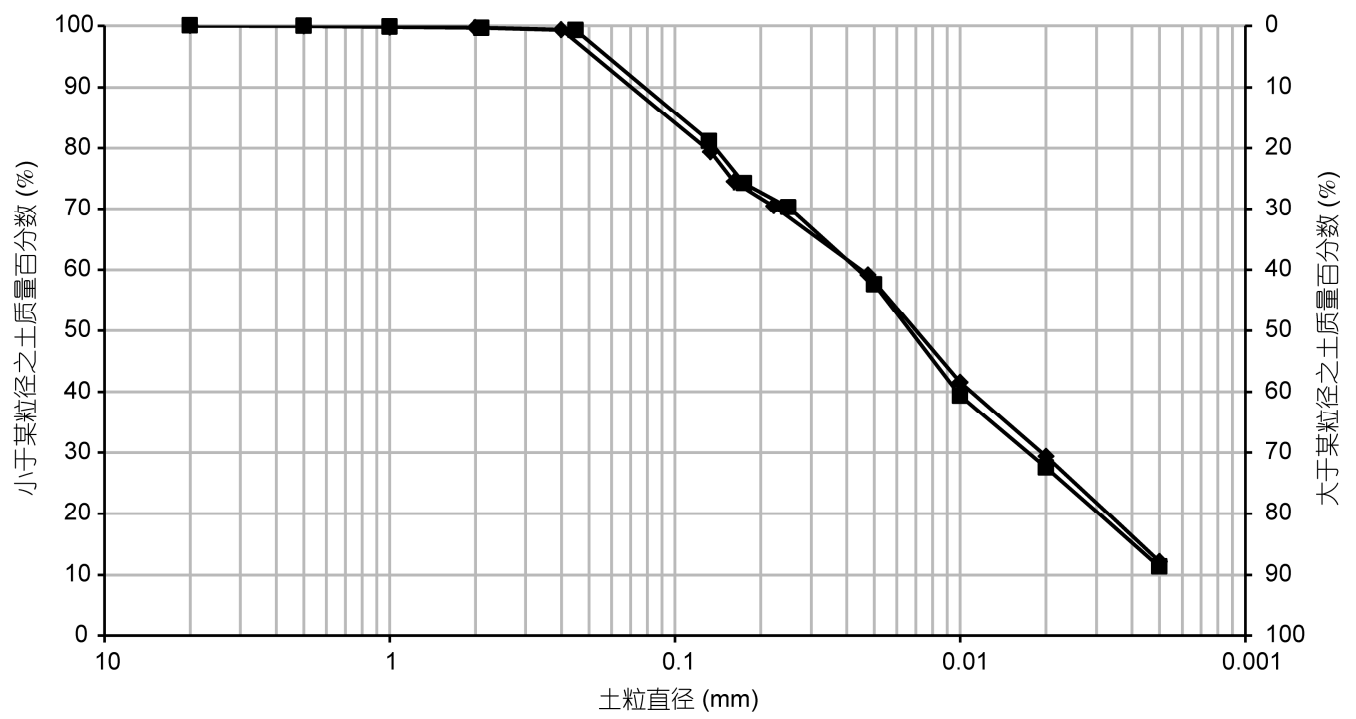

图 5 地基土级配曲线图

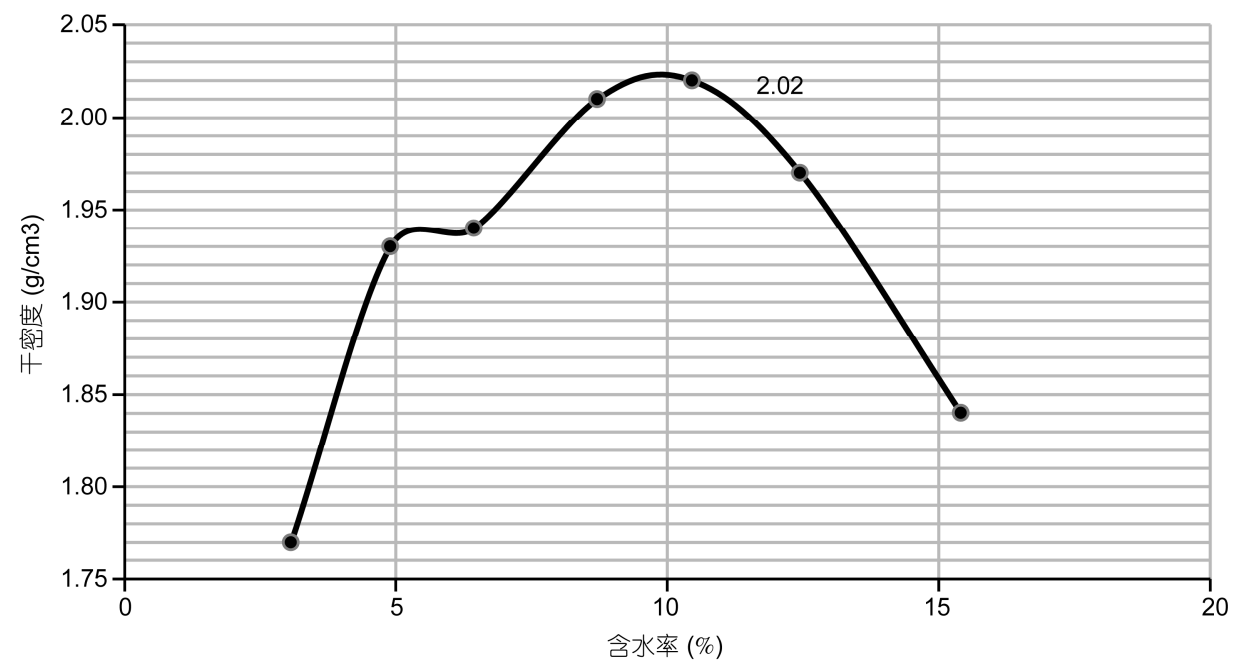

图 6 击实试验曲线图

\section{表 3 地基土基本物性指标}

\begin{tabular}{lc}
\hline \multicolumn{1}{c}{ 物性指标 } & 数值 \\
\hline 液限 $(\%) h=10 \mathrm{~mm} / h=17 \mathrm{~mm}$ & $33.50 / 38.80$ \\
塑限 $(\%)$ & 21.50 \\
塑性指数 $10 \mathrm{~mm} / 17 \mathrm{~mm}$ & $12.03(17.30)$ \\
颗粒密度 $\left(\mathrm{g} / \mathrm{cm}^{3}\right)$ & 2.69 \\
最佳含水率 $(\%)$ & 10.00 \\
最大干密度 $\left(\mathrm{g} / \mathrm{cm}^{3}\right)$ & 2.02 \\
\hline
\end{tabular}

$11.74 \%$ ，土样属于低液限粉质黏土为 C 组填料.

模型填土按最优含水率 $10 \%$ 进行配制, 分四层填
筑, 从下至上, 厚度分别为 $0.2,0.3,0.3$ 和 $0.2 \mathrm{~m}$. 共进 行三组模型试验, 压实系数分别按 $K=0.9,0.95,1.0$ 控 制, 准确称量每层填土的质量, 摊平后进行人工夯实.

为降低模型填土在试验期间的水分损失, 通过 实验获得了模型填土维持 $10 \%$ 含水率的最佳空气相 对湿度为 $92 \%$, 依此, 采用薄膜对试验空间、墙土边 界、模型表面进行多层封闭, 并通过加湿器保持薄膜 内相对空气湿度不低于 $92 \%$.

模型填筑完成之后, 参照《铁路工程土工试验规 程 $\rangle^{[28]}$ 开展地基系数 $K_{30}$ 试验, 得到 $K=0.9,0.95,1.0$ 压实条件下的 $K_{30}$ 值分别为 $76,100,118 \mathrm{MPa} / \mathrm{m}$, 由经 
验公式 ${ }^{[29]}(15)$ 得到模型地基的基本承载力 $[\sigma]$, 地基 极限承载力 $\sigma_{f}$ 按 $(16)$ 式进行估算.

$$
\begin{gathered}
{[\sigma]=2.4 K_{30}+15,} \\
\sigma_{f}=2[\sigma] .
\end{gathered}
$$

式(12)中, $K_{30}$ 单位取 $\mathrm{MPa} / \mathrm{m}$, [ $\sigma$ ]单位取 $\mathrm{kPa}$. 得到填 土模型的极限承载力分别为 394,510 和 $596 \mathrm{kPa}$, 经 验表明, 由 $0.3 \mathrm{~m}$ 直径的小型加载板试验得到的承载 力值较常规载荷试验 ${ }^{[13]}$ 测试值偏小.

分别对三种压实条件下的单元结构填土模型, 进行了分级加载的变形时间效应测试. 每级正式加
载前进行两次加卸载循环, 加卸载分别保持 2 和 $5 \mathrm{~min}$, 测定该级荷载的回弹变形. 分级加载的第 $i$ 级荷载 $p_{i}$ 按(17)式确定，并保持 $24 \mathrm{~h}$.

$$
p_{i}=\lambda_{i} \sigma_{f},
$$

式中, $i$ 为加载级数: $1,2,3, \cdots, \lambda_{i}$ 为荷载水平, 依次取 $5 \%, 10 \%, 20 \%, 30 \%, \cdots$.

通过变形时程曲线和当前荷载下的回弹变形, 得到该级荷载下的塑性变形 $S_{P}$ 时程曲线. 图 7 为 $K=$ 0.90 模型在荷载 $p=0.05 \sigma_{f}, 0.2 \sigma_{f}, 0.4 \sigma_{f}, 0.6 \sigma_{f}, p=0.7 \sigma_{f}$ 和 $0.85 \sigma_{f}$ 下 $S_{P}$ 时程曲线; 图 8 为 $K=0.95$ 模型在荷载

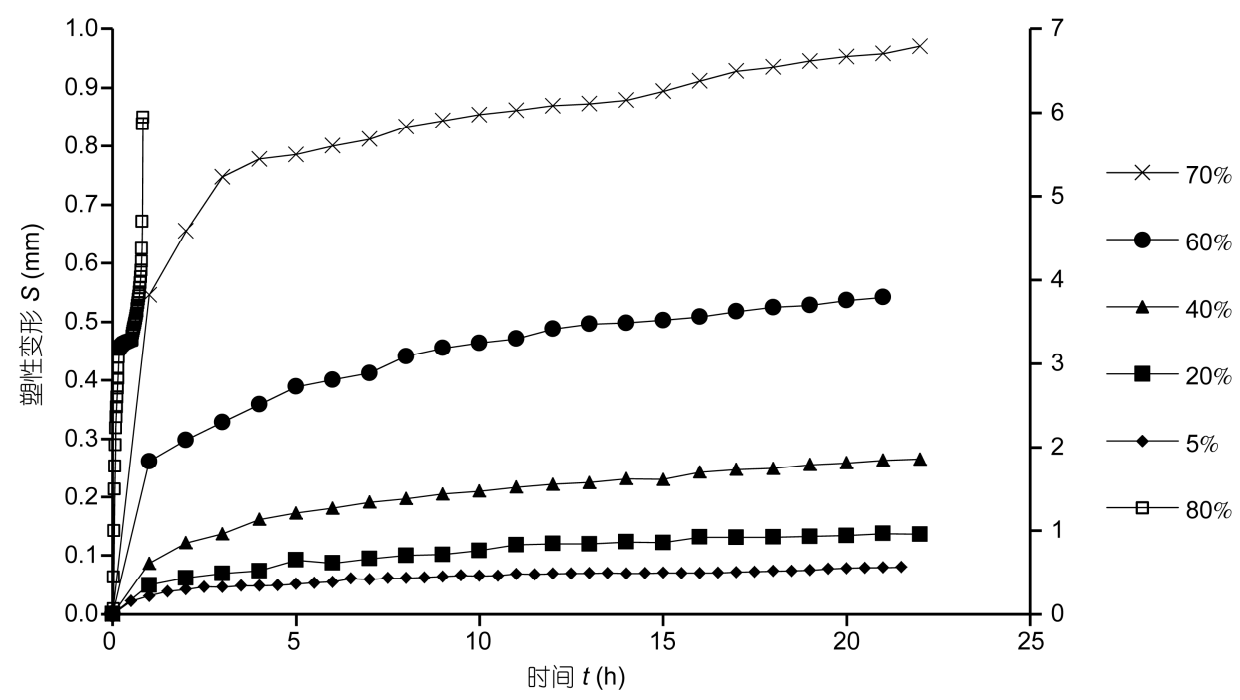

图 $7 S_{P^{-}-t}$ 曲线 $(K=0.90)$

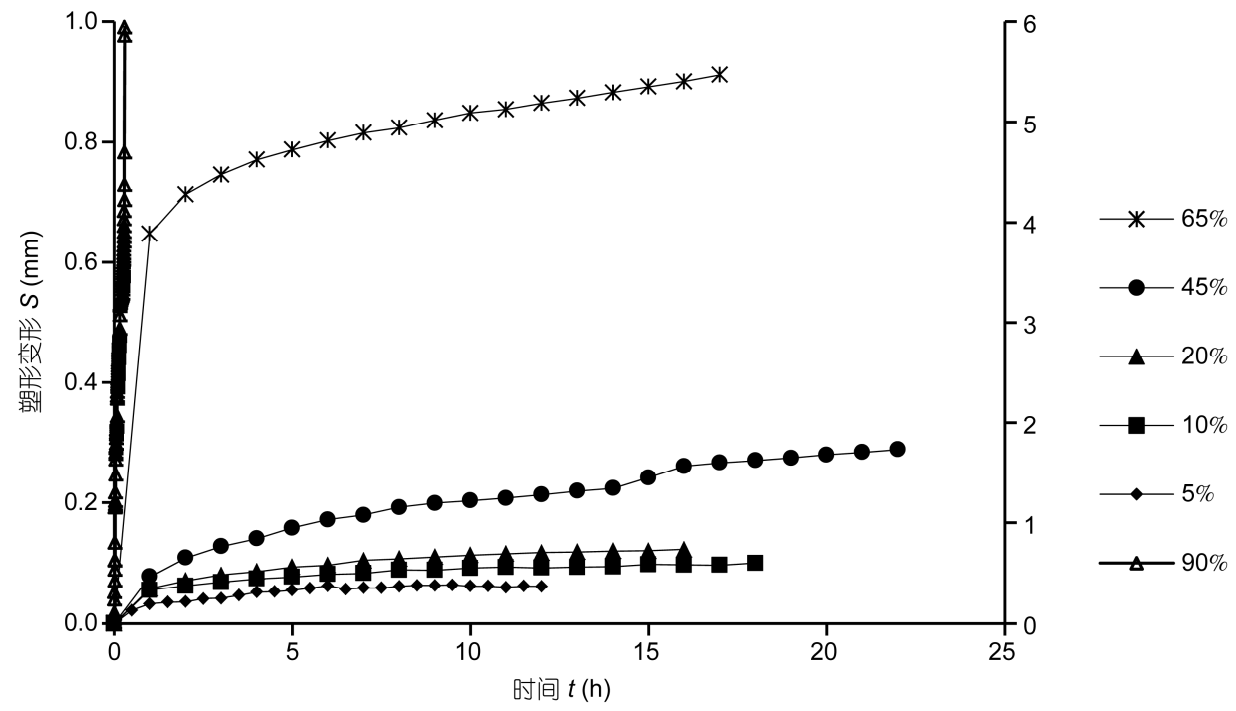

图 $8 S_{P-t} t$ 曲线 $(K=0.95)$ 
$p=0.05 \sigma_{f}, 0.1 \sigma_{f}, 0.2 \sigma_{f}, 0.45 \sigma_{f}$ 和 $0.65 \sigma_{f}$ 下 $S_{P}$ 时程曲线; 图 9 为 $K=0.95$ 模型在荷载 $0.05 \sigma_{f}, 0.2 \sigma_{f}, 0.3 \sigma_{f}, 0.4 \sigma_{f}$ 和 $0.6 \sigma_{f}$ 下 $S_{P}$ 时程曲线. 各模型最后一级按次坐标轴 显示.

利用 $S_{P^{-}} t$ 曲线得到塑性变形速率前需确定塑性 变形速率时间标度 $\delta$ 和无标度区间 $T$. 变形过程的速 率分形, 不存在无穷套嵌结构 ${ }^{[20]}$, 对变形速率 $v$ 和时 间 $t$ 取双对数可得二者线性关系 $\ln v=-D \ln t$ 区域，该 区域时间范围即无标度区间 $T$, 如图 10. 分维数的数 学定义要求 $\delta \rightarrow 0$ 时极限存在, 但是 $\delta$ 太小测量系统 偶然噪声 ${ }^{[27]}$ 会表现出现, 必须按测量精度设置最小 时间标度 $\delta_{\min }$. $\delta$ 越小并且到达一定的套嵌次数, 测
量维数 $D$ 越接近理论维数 $D$ 理论 ${ }^{[20]}$, 选取 $\delta$ 时尽量接 近 $\delta_{\text {min }}$. 选取 $\delta$ 过大时 $v(t)$ 包含变形系统过程的信息 过少, 达不到描述该过程的最少变量个数 $N_{\min }{ }^{[27]}$, 必 须按 $N_{\min }$ 设置最大时间标度 $\delta_{\text {max }} \delta$ 应该满足(18)式.

$$
\delta_{\min } \leqslant \delta \leqslant \delta_{\max },
$$

式中, $\delta_{\text {max }}=T / N_{\text {min }}$.

考虑位移量测精度为 $0.003 \sim 0.005 \mathrm{~mm}$, 同时为 满足较小荷载水平最少变量个数 $N_{\min }$ (取为 3 ), 数据 处理均取时间标度 $\delta=1 \mathrm{~h}$, 荷载较小取 $\delta=0.5 \mathrm{~h}$.

按此原则, 得到塑性变形速率 $V$, 将各级荷载的 无标度区间 $T$ 内速率变化规律通过半对数坐标呈现,

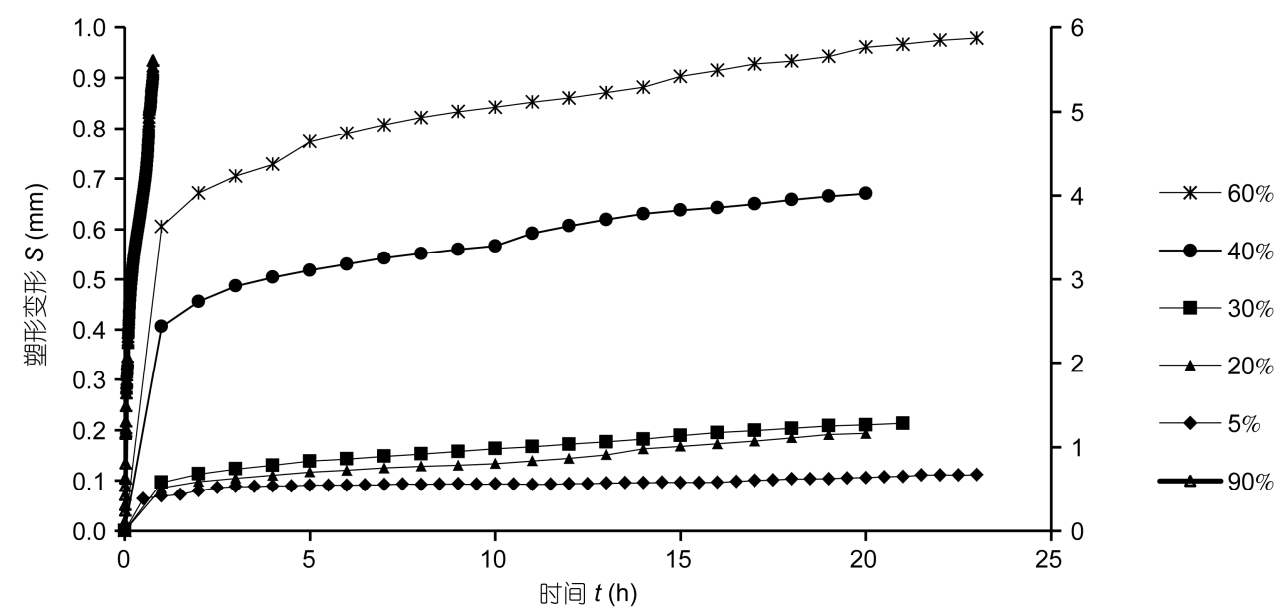

图 $9 S_{P^{-}} t$ 曲线 $(K=1.0)$

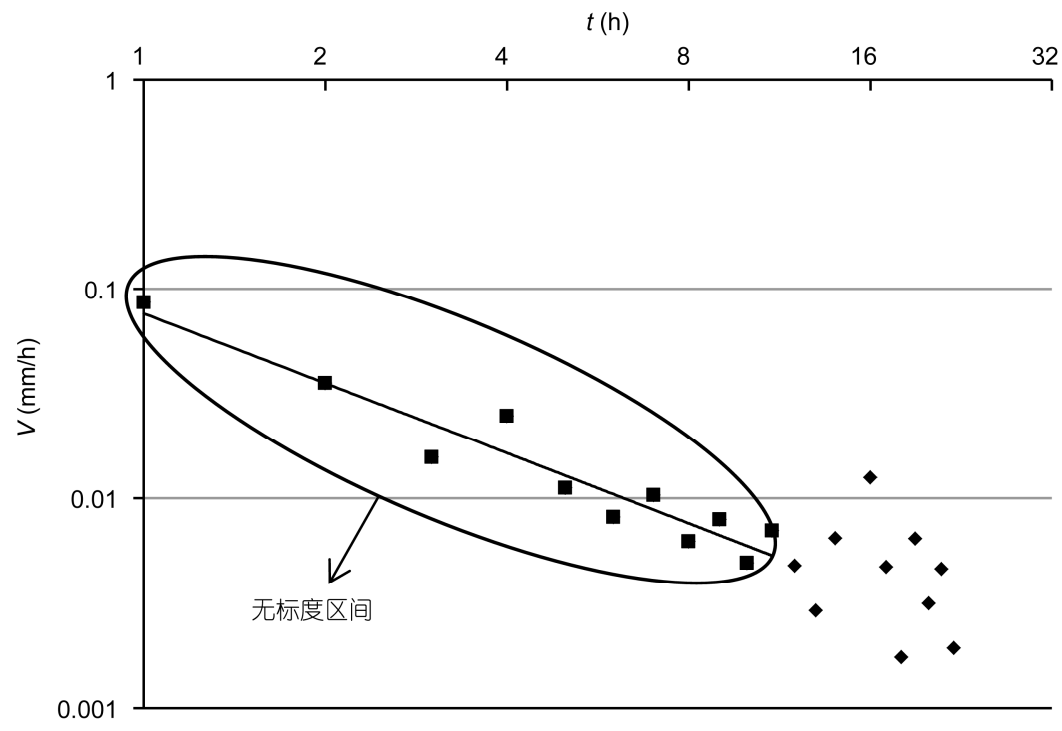

图 10 速率 $v$ 随时间 $t$ 分布无标度区间 
得到不同荷载下的 $D$ 值. 现以 $K=0.90$ 模型为例求 $D$, 如图 11 和 12 .

按上处理可得 $K=0.90$ 模型在试验荷载 $p=0.05 \sigma_{f}$, $p=0.2 \sigma_{f}, p=0.4 \sigma_{f}, p=0.6 \sigma_{f}, p=0.7 \sigma_{f}$ 下的对应的分维值
$D$ 依次为 $2.24,1.68,1.10,0.97$ 和 0.79. 对 $K=0.95$ 和 $K=1.0$ 模型进行同样处理, 得到每级荷载下模型的塑 性变形速率随时间的分维数 $D$, 分维值 $D=0$ 时模型出 现等速流动阶段, 结果汇总如表 4 和图 13 所示.

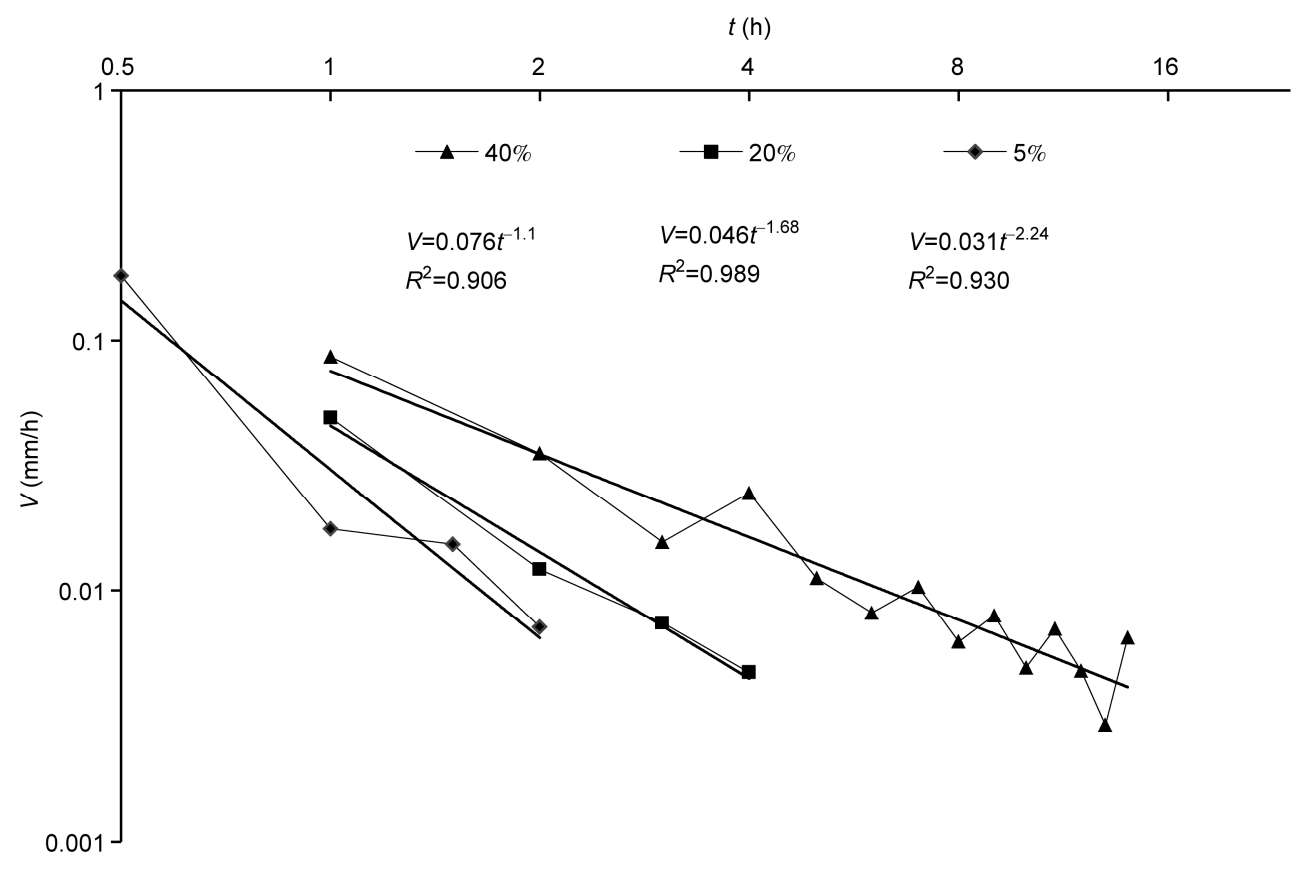

图 $110.05 \sigma_{f}, 0.2 \sigma_{f}$ 和 $0.4 \sigma_{f}$ 下 $V-t$ 曲线 $(K=0.90)$

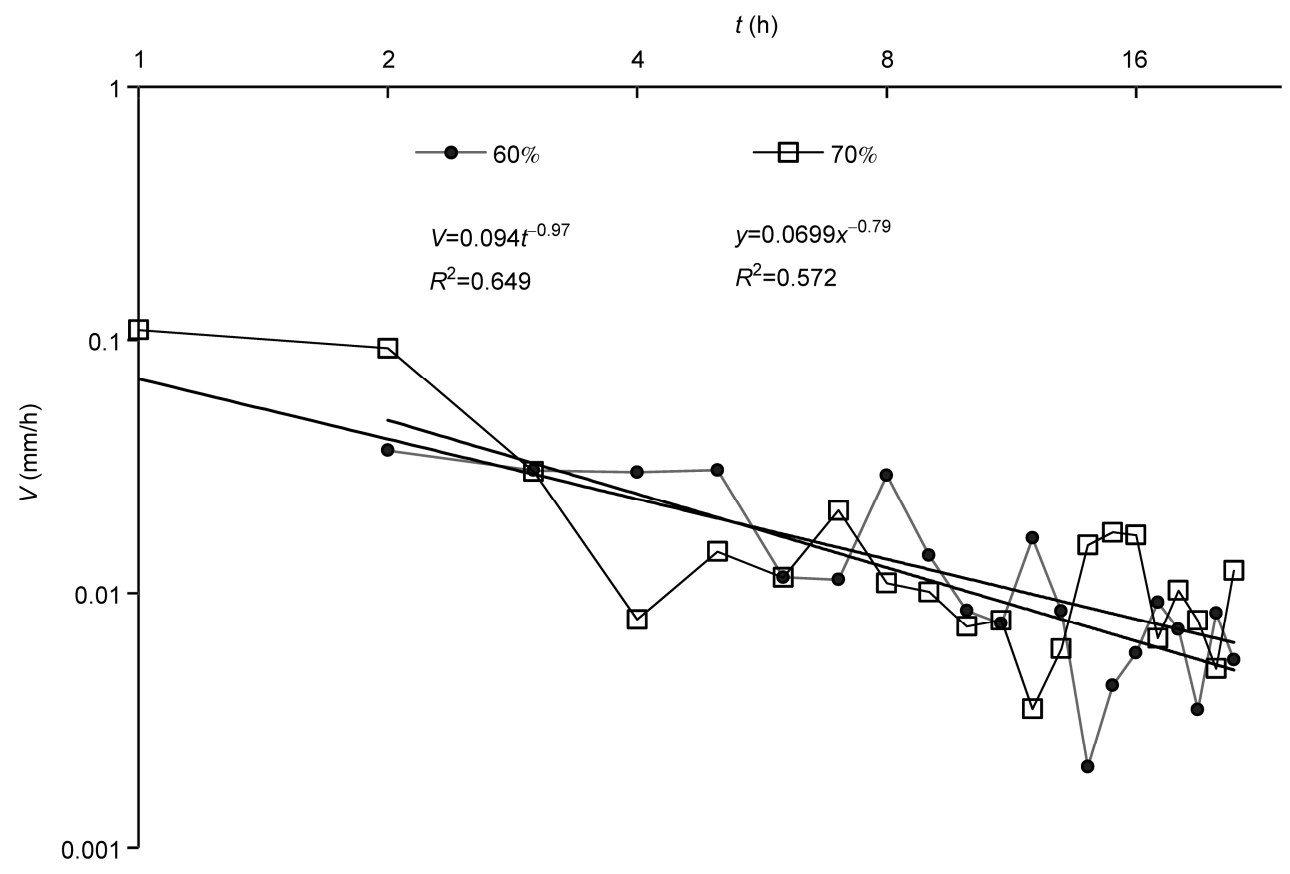

图 $120.6 \sigma_{f}$ 和 $0.7 \sigma_{f}$ 下 $V-t$ 曲线 $(K=0.90)$ 
表 $4 D$ 值汇总表

\begin{tabular}{ccccccc}
\hline \multicolumn{7}{c}{$\frac{\lambda_{i}}{D_{i}}$} \\
\hline $90 \%$ & $\frac{5 \%}{2.24}$ & $\frac{20 \%}{1.68}$ & $\frac{40 \%}{1.1}$ & $\frac{60 \%}{0.97}$ & $\frac{70 \%}{0.79}$ & $\frac{80 \%}{0}$ \\
$95 \%$ & $\frac{5 \%}{2.38}$ & $\frac{10 \%}{1.68}$ & $\frac{20 \%}{1.35}$ & $\frac{45 \%}{0.91}$ & $\frac{65 \%}{0.85}$ & $\frac{90 \%}{0}$ \\
$100 \%$ & $\frac{5 \%}{2.06}$ & $\frac{20 \%}{1.45}$ & $\frac{30 \%}{1.37}$ & $\frac{40 \%}{1.2}$ & $\frac{60 \%}{1.09}$ & $\frac{90 \%}{0}$ \\
\hline
\end{tabular}

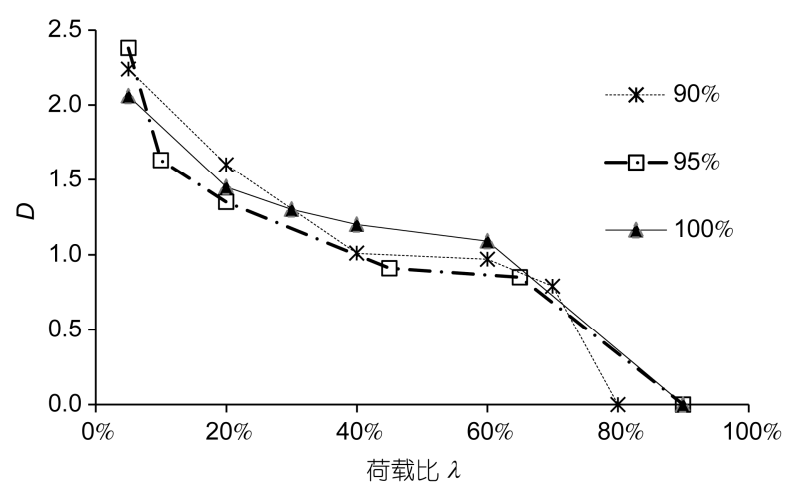

图 $13 D$ - $\lambda$ 变化曲线

根据图 13 的试验曲线, 结合表 2 中的变形状态 判别准则, 可得变形状态划分的荷载水平阈值如表 5 所列. 其中, $D \geqslant 2$ 时, $\lambda<10 \%$, 地基土处于快速稳定状 态, 变形速率急剧衰减, 变形不具有时间效应, 可认 为 $\lambda \approx 10 \%$ 对应的荷载水平为土体结构强度 $p_{c z}$; $1 \leqslant D<2$ 时, $10 \%<\lambda<(50 \% \sim 70 \%)$, 土体处于长期稳定状 态, 塑性变形速率衰减, 变形收玫, $\lambda \approx(50 \% \sim 70 \%)$ 对 应的荷载水平为土体长期静强度 $p_{\infty}$, 与孙钧 ${ }^{[2]}$ 测得 上海淤泥质软土长期强度范围 50\% 80\%比较接近; $0<D<1$ 时, $(50 \% \sim 70 \%)<\lambda<(80 \% \sim 90 \%)$, 土体处于长 期破坏状态, 塑性变形速率不衰减, 变形发散; $D \leqslant 0$ 时, $\lambda \geqslant(80 \%$ 90\%), 此时土体处于快速破坏状态, 接 近极限状态, 此时的荷载水平接近通过 $K_{30}$ 试验根据 (12)和(13)式估算的地基极限承载力.

\section{表 5 粉质黏土变形状态划分的荷载水平阈值}

\begin{tabular}{cc}
\hline 荷载水平 & 变形状态 \\
\hline$\lambda<10 \%$ & 快速稳定 \\
$10 \%<\lambda<(50 \% \sim 70 \%)$ & 长期稳定 \\
$(50 \% \sim 70 \%)<\lambda<(80 \% \sim 90 \%)$ & 长期破坏 \\
$\lambda>(80 \% \sim 90 \%)$ & 快速破坏 \\
\hline
\end{tabular}

实验过程中, $90 \%, 95 \%$ 和 100\%压实度填土模型 回弹变形 $S_{e}$ 与 $\lambda$ 呈近似线性增长关系, 如图 14 所示. 随着压实度从 $90 \%$ 提高到 $95 \%$, 再提高到 $100 \%$, 比 例系数依次为 $2.42,2.58$ 和 2.82 , 变化不大, 近似为 稳定值, 取其平均值 2.46 作为回弹变形线性增长系 数. 由此线性增长关系, 可确定地基变形状态与回弹 变形之间的关系，从而把回弹变形作为鉴别粉质黏 土地基变形状态的参数.

\section{6 具有时效性变形的地基压缩层厚度计算 方法}

\section{1 确定变形状态强度参数}

在应力控制式三轴仪上对单元结构模型填土进 行时间效应的 $\mathrm{CD}$ 试验, 即先在设定围压下使试样固 结 $(24 \mathrm{~h})$, 然后施加偏应力 $\Delta \sigma_{i}$ 按极限偏应力 $\Delta \sigma_{f}$ 的百 分比 ( $\left.\Delta \sigma_{i}=\lambda_{i}^{\prime} \Delta \sigma_{f}, \lambda_{i}^{\prime}=5 \%, 10 \%, 20 \% \cdots\right)$ 对试样进行 分级加载直至破坏, 得到 $D$ 与偏应力水平之间的变 化曲线如图 15, 结合表 2 中的变形状态判别准则, 可

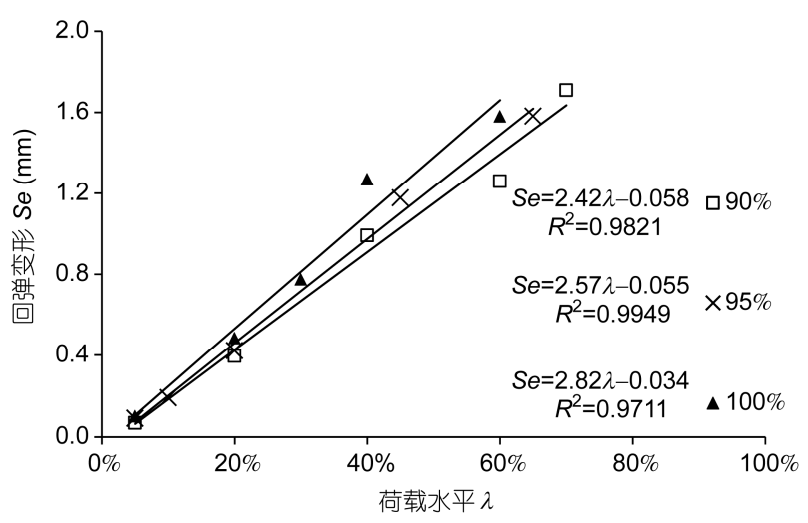

图 14 不同压实度填土模型 $S_{e}-\lambda$ 关系

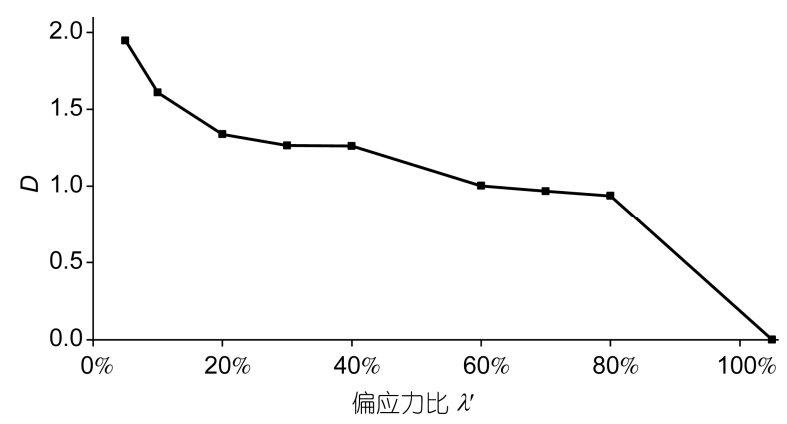

图 $15 \quad D-\lambda$ 变化曲线(三轴) 
得变形状态划分的偏应力水平國值如表 6 所列.

单元结构填土模型试验获得的四种变形状态的 荷载水平阈值(10\%, 50\% 70\% 和 80\% 90\%)与三轴流 变实验得到的偏应力水平阈值(7.9\% 10\%, 60\% 80\% 和 $100 \%$ )是荷载水平和偏应力水平两种方式表达的 变形状态阈值, 二者内涵有所差别, 但数值均接近 $10 \%$.

基于莫尔-库伦准则, 对极限偏应力 $\Delta \sigma_{f}$ 按 $\lambda^{\prime}$ 进行 折减 $\left(B C^{\prime}=\lambda^{\prime} B C, D E^{\prime}=\lambda^{\prime} D E\right)$, 如图 16 所示. 从而 可以通过 $\lambda^{\prime}$ 和极限强度参数 $c$ 和 $\varphi$ 获得土体变形状态 强度参数 $c^{i}$ 和 $\varphi^{i}$ 及其变形状态强度线 $\tau_{f}^{i}=\sigma \tan \varphi^{i}+c^{i}$. 可证明两线都经过 $\mathrm{A}, c^{i}$ 和 $\varphi^{i}$ 满足(19)和(20)式.

$$
\begin{gathered}
\sin \varphi^{i}=\frac{\sin \varphi}{\left[(1-\sin \varphi) / \lambda^{\prime}+\sin \varphi\right]}, \\
c^{i}=\frac{c}{\tan \varphi} \cdot \tan \varphi^{i} .
\end{gathered}
$$

\section{2 具有时效性变形的地基压缩层厚度计算方法}

确定具有变形时间效应的地基压缩层厚度基本 原理是, 以地基承受的坚向附加应力 $\sigma_{z}$ 和坚向自重 应力 $\sigma_{c z}$ 之和作为荷载条件. 以水平自重应力 $\sigma_{c x}$ 为提 供抗剪强度的小主应力, 根据变形状态强度参数 $c^{i}$ 和 $\varphi^{i}$ 和可参照莫尔-库伦准则得到相应的临界大主应力 $\sigma_{\text {max }}^{i}$ 沿深度的变化曲线, 即变形状态强度线. 根据荷 载条件与变形状态强度线的关系, 将地基按变形状

\section{表 6 粉质黏土变形状态划分的偏应力水平國值(三轴)}

\begin{tabular}{cc}
\hline 荷载水平 & 变形状态 \\
\hline$\lambda^{\prime}<(7.9 \% \sim 10 \%)$ & 快速稳定 \\
$(7.9 \% \sim 10 \%)<\lambda^{\prime}<(60 \% \sim 80 \%)$ & 长期稳定 \\
$(60 \% \sim 80 \%)<\lambda^{\prime}<100 \%$ & 长期破坏 \\
$\lambda^{\prime}>100 \%$ & 快速破坏 \\
\hline
\end{tabular}

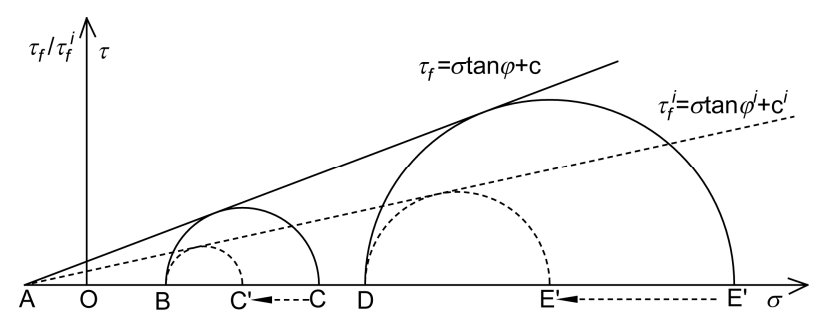

图 16 变形状态强度参数计算原理图
态由上自下划分为快速破坏、长期破坏、长期稳定和 快速稳定的区域, 如图 17 所示. 其中, 快速稳定变形 状态区域以上土层将发生时间效应变形, 对应的地 基深度 $h^{1}$ 即为有时间效应的压缩层厚度, 超过该深 度范围的土层只发生瞬时变形, 对工后沉降无影响.

设自重应力作用下的侧压力系数 $\eta=1$, 可采用 (21)式计算变形状态强度线, 根据(22)式的荷载-变形 状态强度关系, 按快速稳定变形状态强度参数 $c^{\mathrm{I}}$ 和 $\varphi^{\mathrm{I}}$, 可得如(23)式的有时间效应变形的压缩层厚度 $h^{1}$ 控 制方程.

$$
\begin{gathered}
\sigma_{\max }^{i}=\sigma_{c z} \tan ^{2}\left(\pi / 4+\varphi^{i} / 2\right)+2 c^{i} \tan \left(\pi / 4+\varphi^{i} / 2\right), \\
\sigma_{c z}+\sigma_{z}=\sigma_{\max }^{i}, \\
\gamma h^{1}+\sigma_{z}=\gamma h^{1} \tan ^{2}\left(\pi / 4+\varphi^{1} / 2\right)+2 c^{1} \tan \left(\pi / 4+\varphi^{1} / 2\right) .
\end{gathered}
$$

\section{7 计算实例与讨论}

以高速铁路无砟轨道双线路堤地基为例, 开展 具有时效性变形的地基压缩层厚度计算. 路基面宽 $b=13.6 \mathrm{~m}$, 路堤边坡坡率 $i=1: 1.5^{[1]}$, 填土容重 $\gamma_{0}=21$ $\mathrm{kN} / \mathrm{m}^{3}$. 地基为均质土层, 土性同单元结构模型试验 填土, 天然容重 $\gamma=20.7 \mathrm{kN} / \mathrm{m}^{3}$, 天然含水率 $w=18.2 \%$, 标准压缩系数为 $0.104 \mathrm{MPa}^{-1}$, 根据土工试验获得原 状土极限破坏抗剪强度参数 $c$ 和 $\varphi$, 结合三轴试验测 得快速稳定状态荷载阈值范围为 $7.9 \%$ 10\%, 计算压 缩层厚度时, 取 $\lambda^{\prime}=10 \%$, 代入(19)和(20)式中得到快 速稳定状态强度参数 $c^{\mathrm{I}}$ 和 $\varphi^{\mathrm{I}}$ 如表 7 所列.

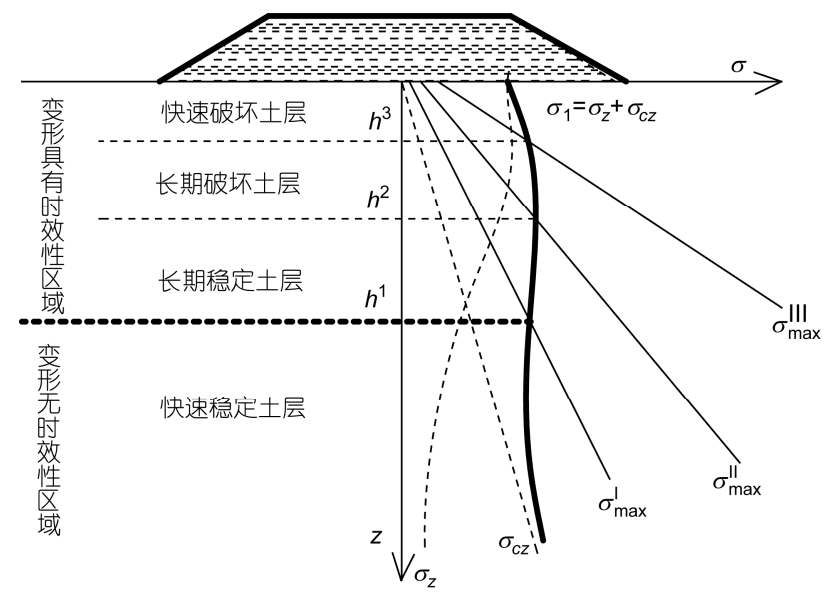

图 17 地基变形状态区域划分 


\section{表 7 极限破坏强度参数和快速稳状态强度参数}

\begin{tabular}{cccc}
\hline$c(\mathrm{kPa})$ & $\varphi\left({ }^{\circ}\right)$ & $c^{\mathrm{I}}(\mathrm{kPa})$ & $\varphi^{\mathrm{I}}\left({ }^{\circ}\right)$ \\
\hline 63.4 & 25.6 & 9.59 & 4.14 \\
\hline
\end{tabular}

采用带状三角形荷载的 Boussinesq 解叠加得到 路堤荷载作用的附加应力 $\sigma_{z}$ 在路堤中线下沿地基深 度的分布. 利用(20)式计算路堤高度分别为 $3,6,9,12$, 15 和 $18 \mathrm{~m}$ 时具有时间效应变形的地基缩层厚度 $h^{1}$. 同时, 采用应力比法按 $\psi=0.1,0.2,0.3$ 和 0.5 分别确定 高度为 3, 6, 9, 12, 15 和 $18 \mathrm{~m}$ 路堤下地基压缩层厚度, 如表 9 和图 18 所示.

对于高速铁路无砟轨道双线路堤, 边坡坡率 $i$, 路 堤填土容重 $\gamma_{0}$ 和路基面宽 $b$ 等均不变, 时间效应法确 定的地基压缩层厚度 $h^{1}$ 随 $H$ 变化, 与应力比法确定 的地基压缩层厚度 $Z_{n}$ 变化规律一致, 近似呈线性增 长, 与应力比法按 $\psi=0.2$ 确定的压缩层厚度基本一 致, 可见应力比法对非高压缩性土地基取 $\psi<0.2$

表 8 不同 $\boldsymbol{h}^{1}$ 和 $Z_{n}$ 随路堤高度 $\boldsymbol{H}$ 变化

\begin{tabular}{|c|c|c|c|c|c|c|c|}
\hline & $H(\mathrm{~m})$ & 3 & 6 & 9 & 12 & 15 & 18 \\
\hline & $h^{1}(\mathrm{~m})$ & 10 & 19 & 27 & 34 & 41 & 48 \\
\hline \multirow{4}{*}{$Z_{n}(\mathrm{~m})$} & $\psi=0.1$ & 18 & 29 & 39 & 48 & 58 & 65 \\
\hline & $\psi=0.2$ & 12 & 19 & 26 & 33 & 39 & 46 \\
\hline & $\psi=0.3$ & 9 & 15 & 21 & 26 & 31 & 35 \\
\hline & $\psi=0.5$ & 6 & 11 & 15 & 19 & 22 & 26 \\
\hline
\end{tabular}

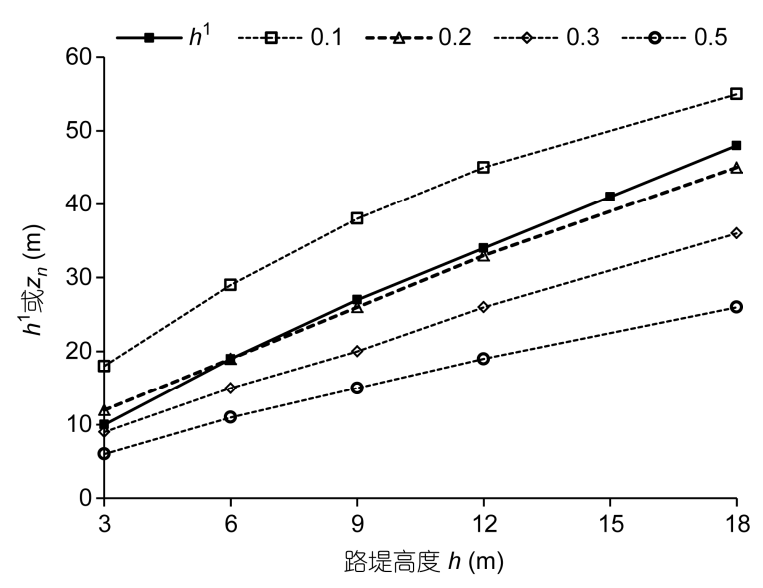

图 18 不同 $K, H$ 和 $m$ 时 $h_{1}$ 和 $Z_{n}$ 变化曲线
基本可以保证地基变形不具有时间效应, 高速铁路 取 $\psi=0.1^{[4]}$ 对中低压缩性土地基偏严.

\section{8 结论}

针对路基工程以工后沉降为控制目标的特点, 开展了土体变形时间效应及状态演变的研究, 分析 了路堤荷载作用下地基中具有不同时间效应变形特 征的土层沿深度分布情况. 有以下结论

1) 提出了长期荷载作用下土体变形呈现快速稳 定、长期稳定、长期破坏和快速破坏的四种状态类别; 基于分形的无标度性特征, 确定了变形速率 $v(t)$ 随时 间 $t$ 具有分形特性，建立了基于分维数 $D$ 的变形状态 判别准则, 即 $D>2$, 为快速稳定状态, 变形无时间效 应; $1<D<2$, 为长期稳定状态, 变形最终稳定但有时 间效应; $0<D<1$, 变形状态为长期破坏状态, 变形最 终发散并表现出时间效应; $D<0$, 变形为快速破坏 状态.

2) 设计构筑了粉质黏土在 $100 \%, 95 \%$ 和 $90 \%$ 压 实条件下的单元结构填土模型试验，实现了不同荷 载水平作用下土体变形分别处于快速稳定、长期稳 定、长期破坏和快速破坏状态的全类型模拟. 基于分 维数判别准则, 得到了试验条件对应的模型填土变 形状态荷载阈值, 即, 以极限承载力进行归一化处理 后的荷载水平 $\lambda<10 \%$ 对应快速稳定状态， $10 \%<\lambda<$ (50\% 70\%) 对应长期稳定状态， $(50 \%$ 70\%) $<\lambda<$ (80\% 90\%) 对应长期破坏状态， $\lambda>(80 \% ~ 90 \%)$ 对应快 速破坏状态. 建立的地基土变形状态荷载阈值模型 试验方法为采用“时间效应法”确定高速铁路地基压 缩层厚度所需的变形状态参数选取提供了依据.

3）建立了基于变形时间效应的高速铁路地基压 缩层厚度计算方法, 即, 基于莫尔-库伦准则, 建立了 土体变形状态强度参数 $c^{i}$ 和 $\varphi^{i}$ 与极限破坏强度参数 $c$ 和 $\varphi$ 的关系，根据地基土中应力与变形状态强度线的 关系, 将地基按变形状态由上自下划分为快速破坏、 长期破坏、长期稳定和快速稳定的不同区域，其中， 快速稳定变形状态区域以上土层将发生时间效应变 形，对应的地基深度 $h^{1}$ 即为有时间效应的压缩层厚 度. 促进了地基压缩层厚度的确定由经验性取值向 定量力学计算发展. 


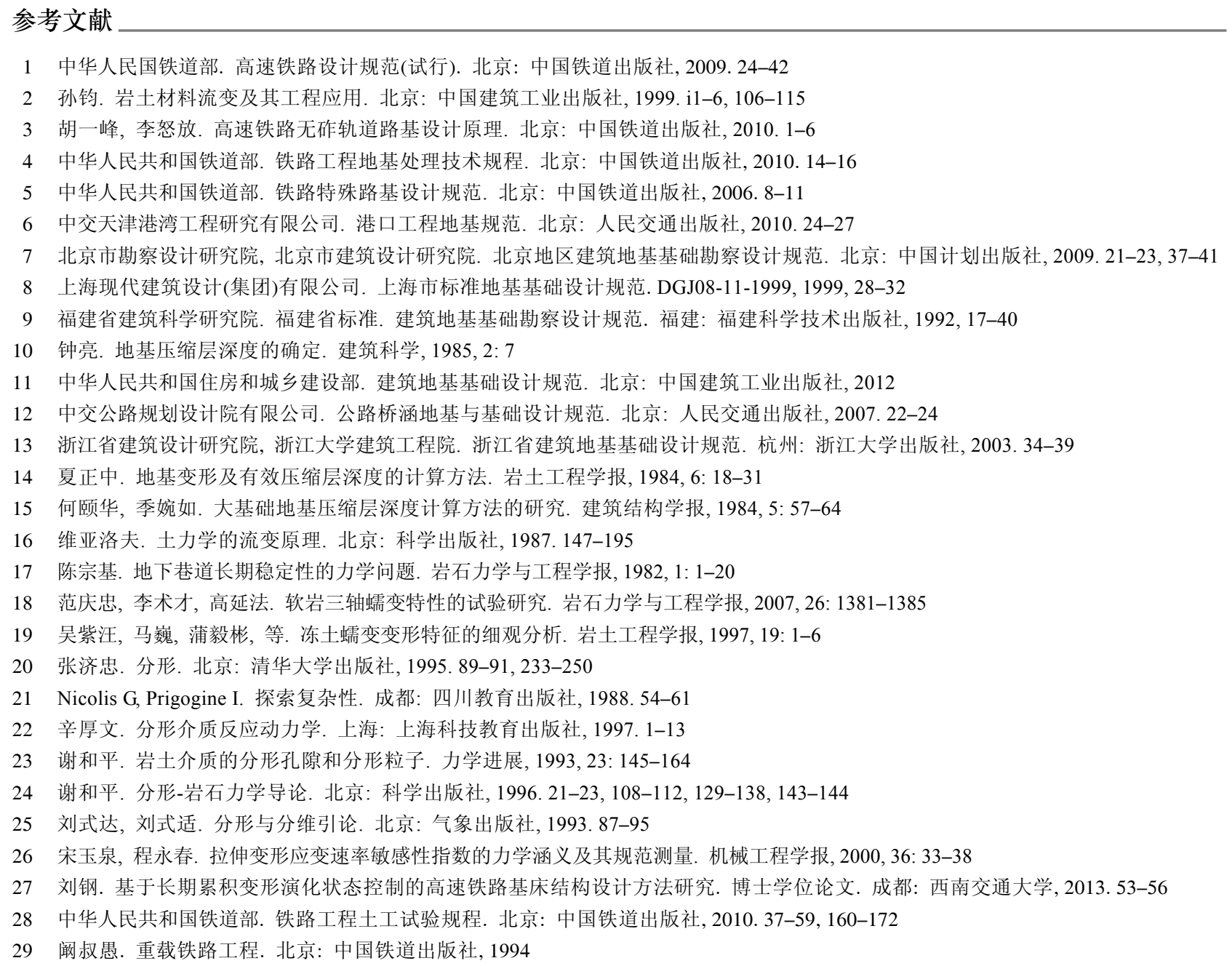

\title{
Calculating method based on deformation time effect on thickness of compressible stratum in high-speed railway foundation
}

\author{
XIONG Yong, LUO Qiang, ZHANG Liang, JIANG LiangWei \& ZHU JiangJiang
}

Key Laboratory of High-speed Railway Engineering, Southwest Jiao tong University, Chengdu 610031, China

Deformation of foundation on embankment load is the main reason of subgrade settlement in high-speed railway, time-effect deformation of foundation is the core element that degrades the long-term service performance of high-speed railway, and determining the foundation area with time-effect deformation is the key point of calculating foundation settlement in order to control the post-construction settlement. Based on the scale-free characteristic of fractal theory, fractal relationship between plastic deformation rate and the time is established, revealing that soil under different load levels presents four kinds deformation evolution states of fast stability, long-term stability, long-term damage and rapidly damage. To discriminate deformation states, the "fractal demention criterion" representing plastic deformation rate variety is put forward. At the same time, the rheological tests on the triaxial and unit 
structure filling model are carried out to obtain the deformation state thresholds of the soft clay with low and medium compressibility, further more the ratios between the thresholds and ultimate shear strength or ultimate bearing capacity experimentally. In view of Mohr-Coulomb criterion, using the equal proportion strength reduction method, state strength parameters on the deformation of foundation soil are received. On account of the stress state of foundation soil, the deformation state controlling equation on Coulomb strength theory is gained, and clear time-effect deformation area of foundation along depth, the thickness of which is thickness of compressible stratum on the foundation time-effect deformation. This calculation method based on deformation time effects on thickness of foundation compressible stratum provides a theoretical basis and experimental support for further improvement of high-speed railway foundation settlement calculation theory.

high-speed railway, embankment foundation, deformation time effect, thickness of compressible stratum, soil rheological experiments

doi: 10.1360/N092014-00087 